\title{
VOC and CO Removals by Perovskite Type Nanocatalysts Supported on Commercial Substrates
}

\author{
Shahriar Hosseinpour ${ }^{1}$, Mahsa Bahramgour ${ }^{1, *}$, Seyyed Reza Hosseini ${ }^{1}$, Yılmaz Yildirim² and \\ Aligholi Niaei ${ }^{1}$ \\ ${ }^{1}$ Reactor \& Catalyst Research Lab., Department of Chemical \& Petroleum Engineering, University of Tabriz,5166616471, Tabriz, \\ Iran \\ ${ }^{2}$ Department of Environmental Engineering, Faculty of Engineering, Zonguldak Bulent Ecevit University, Zonguldak, Turkey
}

\author{
ARTICLE INFO \\ Article Type: Research Article \\ Keywords: \\ Toluene \\ $\gamma$-alumina \\ Perovskite \\ co removal \\ Nanocatalyst \\ Zeolite supports \\ Timeline: \\ Received: June 26, 2021 \\ Accepted: November 02, 2021 \\ Published: November 15, 2021 \\ Citation: Hosseinpour S, Bahramgour M, Hosseini SR, \\ Yildirim Y, Niaei A. VOC and CO Removals by \\ Perovskite Type Nanocatalysts Supported on \\ Commercial Substrates. J Chem Eng Res Updates, \\ 2021; 8: 24-35. \\ DOl: https://doi.org/10.15377/2409-983X.2021.08.2
}

\begin{abstract}
In this research, it was tried to choose a kind of perovskite catalyst with optimized formulation $\mathrm{La}_{0.8} \mathrm{Sr}_{0.2} \mathrm{CO}_{0.66} \mathrm{Fe}_{0.34} \mathrm{O}_{3}$ to remove air pollutants. This perovskite catalyst stabilized on the various supports such as $\gamma$-alumina and ZSM-5 with the sol-gel synthesis technique and ceramic monolith by dip-coating method. Four different catalysts by variable weight percentage including PE-Al 10\%, PE-Al 20\%, PE-Al 30\%, and PE-Al 40\% were prepared by sol-gel synthesis technique. In this work, the XRD technique was used to confirm the formation of perovskite catalysts' crystalline phases on the supports. As a result, XRD patterns revealed the formation of the perovskite phase onto the $\gamma$-alumina and zeolite supports. Activity tests of these four catalysts were examined in the catalytic oxidation of Toluene and CO using an experimental setup consisting of a tubular flow reactor at the temperature $280-400^{\circ} \mathrm{C}$ and $100-400^{\circ} \mathrm{C}$ for the toluene and CO removal systems, respectively. According to the results of the catalysts' activity test, the alumina supported with $40 \% \mathrm{w} / \mathrm{w}$ perovskite catalyst showed the best performance, and its activity was similar to the activity of the bulk catalyst (over $95 \%$ conversion of toluene at about $290^{\circ} \mathrm{C}$ ). For the coated catalysts on a ceramic monolith, the complete removal of carbon monoxide at $50^{\circ} \mathrm{C}$ was lower than the powdered form. Results from the activity test in a toluene removal system that show coating of the bulk and supported catalysts on ceramic monolith; have an essential impact on the activity test of these catalysts.
\end{abstract}

\footnotetext{
*Corresponding Author

Email: m_bahramgur@outlook.com

Tel: +98 4133392985
}

(c) 2021 Pour et al. Published by Avanti Publishers. This is an open access article licensed under the terms of the Creative Commons Attribution NonCommercial License which permits unrestricted, non-commercial use, distribution and reproduction in any medium, provided the work is properly cited. (http://creativecommons.org/licenses/by-nc/4.0/) 


\section{Introduction}

Organic chemicals, including Volatile organic compounds (VOCs) that are released mainly by automobiles and chemical processes, are the most important cause of air pollution. The reaction between VOCs is the main reason for chemical smoke and acid rain formation. Developed methods are used by testers to eliminate VOCs. One of the efficient and economical methods for VOC removal is Catalytic oxidation [1,2]. Carbon monoxide $(\mathrm{CO})$, which is mainly released by fossil fuels that are burned in diesel machines, is the most important cause of gas pollution [3]. Supported noble metal catalysts are used by some industries to remove VOC and CO [4]. However, some of the factors that limit their vast applications are their high cost, their tendency to poisoning and disintegration, and sometimes their poor thermal stability [5]. In recent years, perovskite oxide catalysts with the $\mathrm{ABO}_{3}$ formula have been considered by researchers because of remarkable efficiencies for VOCs and CO oxidation [6-8].

$A$ and $B$ are two different cations in the perovskite structure that $B$ atoms are more petite than $A$ atoms $[9,10]$. Both cations can be slightly substituted to form alternative compounds of the formula $A_{1-x} A_{x}^{\prime} B_{1-y} B_{y}^{\prime} O_{3}[11,12]$. So, by the selection of the proper $A^{\prime}$ and $B^{\prime}$ ions in the mentioned formula, a catalyst with the appropriate activity can be obtained. Replacement of $\mathrm{La}^{3+}$ with either $\mathrm{Sr}^{2+}$ can alter the oxidation state of the transition metal cations, leading to structural defects and an increase in the oxygen vacancy of the perovskite catalysts, which helps to improve the percussion performance [13-15]. Among perovskites, lanthanum manganite, has attracted more attention for toluene $\left(\mathrm{C}_{7} \mathrm{H}_{8}\right)$ and $\mathrm{CO}$ oxidation. This is because of its non-stoichiometric oxygen properties [16].

$\mathrm{LaMnO}_{3}$ activity of the catalyst in toluene $\left(\mathrm{C}_{7} \mathrm{H}_{8}\right)$ and $\mathrm{CO}$ oxidation was investigated by researchers [17-19]. However, about the result of $A$ and $B$ sites substitution on the physical and chemical attributes and catalytic efficiency of $\mathrm{LaMnO}_{3}$ perovskite for toluene $\left(\mathrm{C}_{7} \mathrm{H}_{8}\right)$ and $\mathrm{CO}$ oxidation, much less work has been reported [20].

In recent studies, the support of perovskite catalysts on different bases and the coating of these catalysts on the monolith was mentioned by different researchers. In 2021, Qi et al. utilized a series of perovskites based on $\mathrm{LaNi}_{\mathrm{x}} \mathrm{B}_{1-\mathrm{x}} \mathrm{O}_{3}(\mathrm{~B}=\mathrm{Co}, \mathrm{Cu})$ for toluene removal. These catalysts were synthesized by the sol-gel method. Results revealed the best activity for a 3:1 molar ratio of $\mathrm{Ni} / \mathrm{Co}$ in $\mathrm{LaNi}_{\mathrm{x}} \mathrm{Co}_{1-\mathrm{x}} \mathrm{O}_{3} /$ perovskite [21]. In another study, Li et al. in 2021 performed some researches around the toluene oxidation process that proposed a nano casting array method for the synthesis of $\mathrm{N}-\mathrm{L}_{1-\mathrm{x}} \mathrm{S}_{\mathrm{x}} \mathrm{MO}(\mathrm{x}=0.2,0.5,0.8)$ samples. Results indicated that the Pd@N- $\mathrm{L}_{0.8} \mathrm{~S}_{0.2} \mathrm{MO}$ catalyst with 2 wt\% revealed the best stability [22]. In 2021, Liu et al. developed a workaround VOC (benzene and chlorobenzene) degradation using Porous $\mathrm{Mn}$-based mullite $\mathrm{SmMn}_{2} \mathrm{O}_{5}$ perovskite catalyst. The synthesis procedure of mentioned catalyst was the in-situ dismutation method. This porous catalyst revealed better catalytic results compared to the bulk $\mathrm{SmMnO}_{3}$ and bulk $\mathrm{SmMn}_{2} \mathrm{O}_{5}$ [23]. Moreover, in another study, Yi et al. in 2021 investigated the removal of benzene as $\mathrm{VOC}$ via $\mathrm{Pd}-\mathrm{CeMnO}_{3}$ perovskite catalyst through the combination of sol-gel and impregnation methods. Results showed that using different Pd and Ce ions lead to the generation of more active oxygen. This helps to the facile activation of the benzene rings [24]. Regarding the replacement results, sites $\mathrm{A}$ and $\mathrm{B}$ report much less work on the physical and chemical properties and catalytic performance of $\mathrm{LaMnO}_{3}$ perovskite for toluene $\left(\mathrm{C}_{7} \mathrm{H}_{8}\right)$ and $\mathrm{CO}$ oxidation, so the study focuses on this issue.

Therefore, in this paper, perovskites were synthesized by sol-gel technique and their catalytic activity for oxidation of toluene and $\mathrm{CO}$ was investigated. The perovskite catalyst with the optimized formulation $\mathrm{La}_{0.8} \mathrm{Sr}_{0.2} \mathrm{CO}_{0.66} \mathrm{Fe}_{0.34} \mathrm{O}_{3}$ was selected to remove gaseous pollutants, i.e., toluene and $\mathrm{CO}$ oxidation. Also, to overcome the low surface area and sintering of these active catalysts, it is possible to stabilize them on commercial supports such as alumina and monolith with high surface area and thermal resistance. Both of these catalysts are synthesized in bulk and supported on bases such as gamma-alumina and zeolite, etc. by the sol-gel synthesis technique, and their activity in pollutant removal (toluene and CO oxidation) was investigated.

\section{Materials and Methods}

\subsection{Catalyst Preparation}

The perovskite with the $\mathrm{La}_{0.8} \mathrm{Sr}_{0.2} \mathrm{CO}_{0.66} \mathrm{Fe}_{0.34} \mathrm{O}_{3}$ general formula was manufactured by the sol-gel technique. $\mathrm{La}\left(\mathrm{NO}_{3}\right)_{3} \cdot 6 \mathrm{H}_{2} \mathrm{O}, \operatorname{Sr}\left(\mathrm{NO}_{3}\right)_{2}, \mathrm{Fe}\left(\mathrm{NO}_{3}\right)_{3} \cdot 6 \mathrm{H}_{2} \mathrm{O}$, and $\mathrm{CO}\left(\mathrm{NO}_{3}\right)_{2} \cdot 6 \mathrm{H}_{2} \mathrm{O}$, purchased from Merck/Aldrich, was dissolved in 
deionized water with appropriate ratios. Heat the solution in a hotplate to $70^{\circ} \mathrm{C}$ and then slowly add citric acid $\left(\mathrm{C}_{6} \mathrm{H}_{8} \mathrm{O}_{7}\right)$ (Merck) to the solution. The molar ratio of citric acid $\left(\mathrm{C}_{6} \mathrm{H}_{8} \mathrm{O}_{7}\right)$ per total nitrate was 0.255 in solution. The subsequent combination is heated to $80^{\circ} \mathrm{C}$ and vaporized until a tacky gel is gotten. For gel decomposition, the temperature was raised to $200^{\circ} \mathrm{C}$ to burn the contents and twisted into a dark powder. The dark powder was calcined for 5 hours in a high-temperature oven at $700^{\circ} \mathrm{C}$ to remove volatile compounds and increase stability. The sol-gel synthesis technique, as defined in another work [25], was used to synthesis the mentioned perovskite catalysts in this work. The samples catalyzed coated on monolith, were coated via dip-coating method similar to the procedure that was defined in the literature [26]. In this way, the monoliths were dipped and withdrawn in the custom slurry at a constant speed. Figure 1 illustrates this process for further understanding.

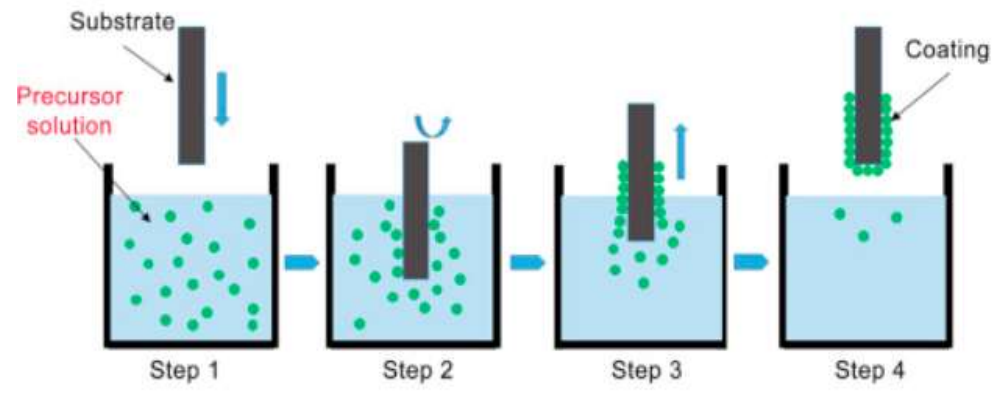

Figure 1: Graphical representation of dip-coating technique [27].

\subsection{Catalyst Activity Test}

Figures 2 and $\mathbf{3}$ shows the catalytic setup simple scheme used in this work. The efficiency of the catalytic instances was calculated by toluene and CO burning in a glass pipe (inner diameter $=8 \mathrm{~mm}$ ), which was placed in a furnace as a heating chamber with electricity being the heat source having isothermal conditions though at work below atmospheric pressure. In any run, $200 \mathrm{mg}$ of the catalyst was used for the activity tests. Considering Equation 1, The hourly gas flow space velocity (GHSV) was $5000 \mathrm{~h}^{-1}$, and the temperature of reaction ranged from $100-400{ }^{\circ} \mathrm{C}$ for the CO system and ranged from $280-400^{\circ} \mathrm{C}$ for the toluene system. In the toluene system, the overall rate of volumetric flow rate was $70 \mathrm{~mL} \mathrm{~min}-1$, and the composition of gas was $\mathrm{N}_{2}=30 \mathrm{~mL} \mathrm{~min}^{-1}$, the composition of the air and toluene $=40 \mathrm{~mL} \mathrm{~min}^{-1}$. In the CO system, the overall rate of volumetric flow was $200 \mathrm{~mL}$ $\mathrm{min}^{-1}$, and the composition of gas was $3000 \mathrm{ppm} \mathrm{CO}$ and $5 \%$ volume $\mathrm{O}_{2}$ stabled with Ar. The rate of conversion was obtained by calculating the concentrations of components as reactants and products of the reactor at various temperatures. The reactants and produces were investigated by gas chromatography (GC-2010) with a flame ionization detector (FID) From Shimadzu brand prepared.

$$
\text { GHSV }=\frac{\text { Total volumetric gaseous feed flow rate to the reactor }}{\text { Total catalyst volume }}[=] \mathrm{h}^{-1}
$$

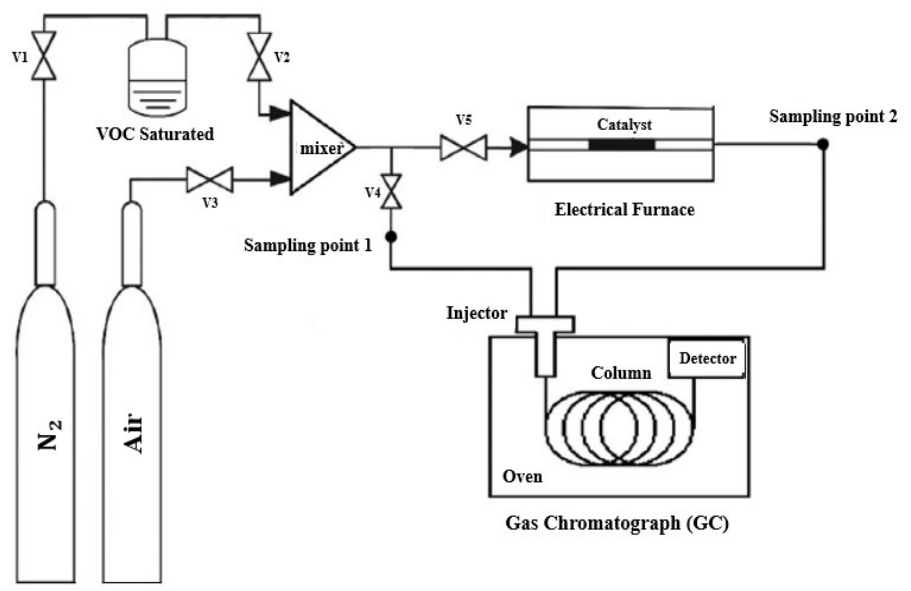

Figure 2: Experimental setup for Activity Test in toluene catalytic oxidation system. 


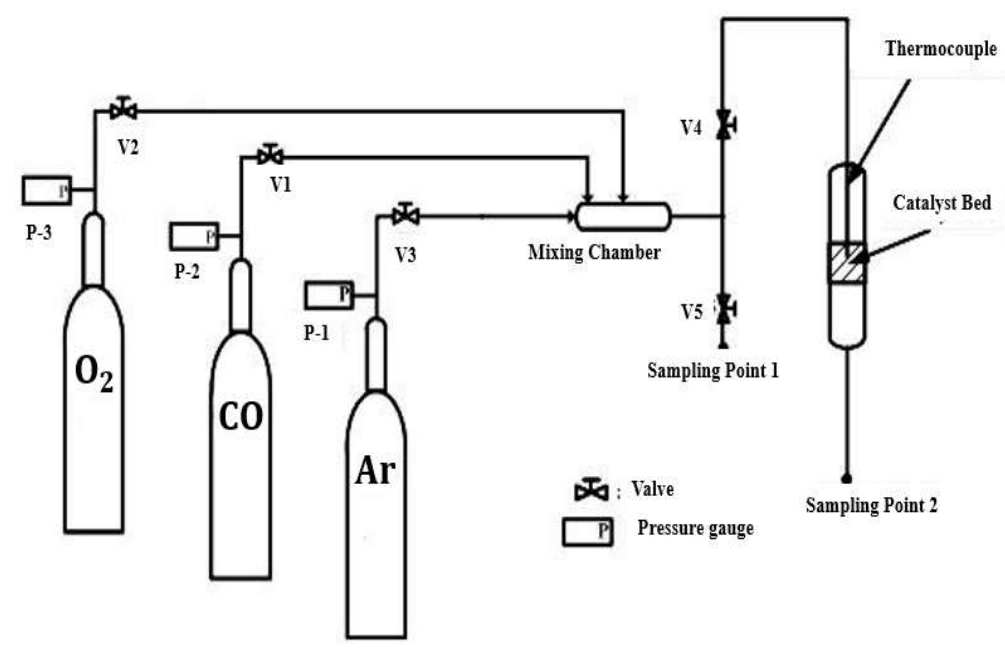

Figure 3: Experimental setup for Activity Test in CO catalytic oxidation system.

\section{Results and Discussion}

\subsection{Catalyst Structure and Characteristics}

According to the XRD patterns obtained for all four catalysts (Figures $\mathbf{4}$ and $\mathbf{5}$ ), they show a peak of the perovskite phase. However, in the catalyst $10 \%$, due to the low amount of perovskite phase, the interaction between the active phase and the support phase is more substantial, and the prominent peaks are not observed by the XRD results. Most of the $\gamma$-alumina X-ray diffraction pattern is apparent. With the increase in perovskite amount in the supported catalysts, the peak intensities appear for the catalysts of 20,30 , and $40 \%$, respectively.

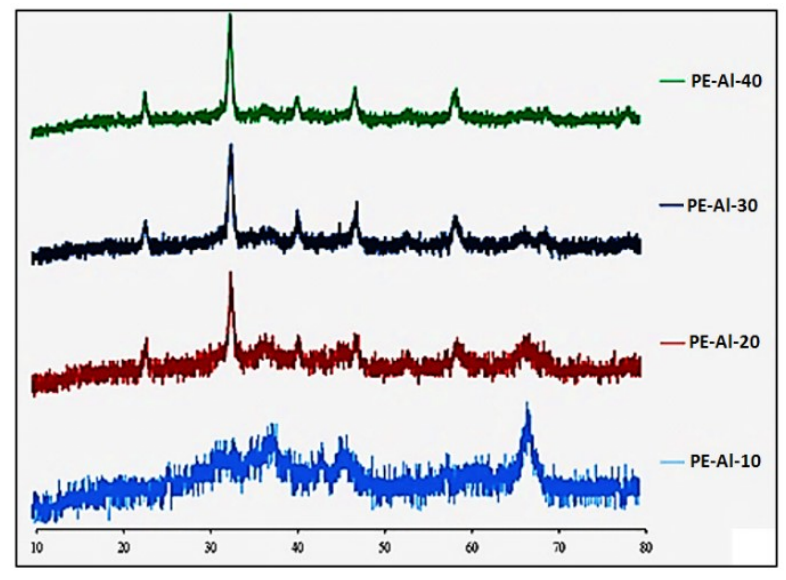

Figure 4: XRD characteristics of different \%Perovskites / Alumina Support

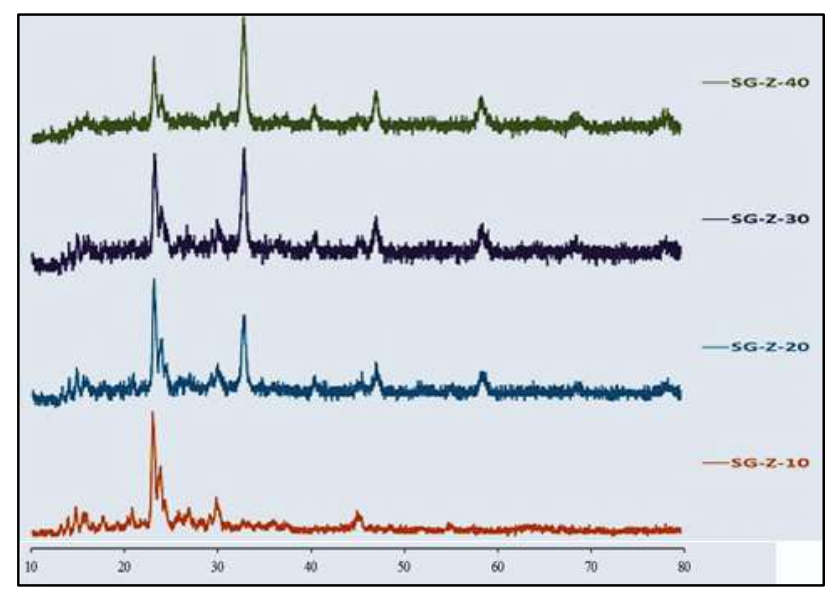

Figure 5: XRD characteristics of different \%Perovskites / ZSM-5 Support

To study the effect of catalyst coating on a monolith in toluene and CO catalytic oxidation systems, the applied monolithic fragments were considered $2 \mathrm{~cm}$ in diameter in both systems and with $5 \mathrm{~cm}$ lengths for toluene and 1 $\mathrm{cm}$ lengths for CO system. The amount of catalyst coated on both monoliths was about $90 \mathrm{mg}$. Figure 6 demonstrates the illustration of these monolithic fragments before and after the catalyst coating on them.

Figure 7 illustrates the scanning electron microscopy (SEM) images of superficial morphology and dimension sizes of the bulk perovskite catalyst particles. As stated by these images, the particle sizes are less than $100 \mathrm{~nm}$. The high-magnification images show that the catalyst particles are in sheet forms and together in a cumulative plane. 


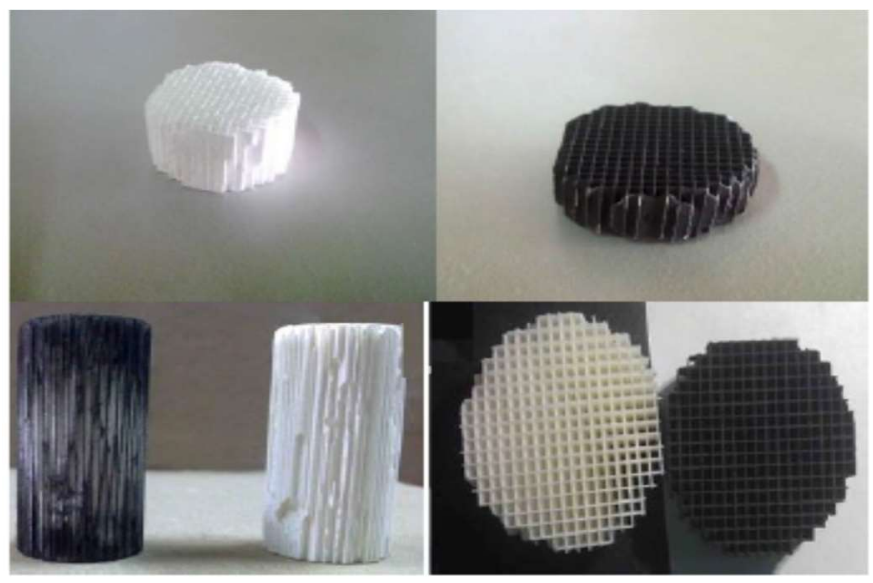

Figure 6: Dip Coated Monoliths with Perovskite. The images above are related to CO systems, and below is related to the toluene system.
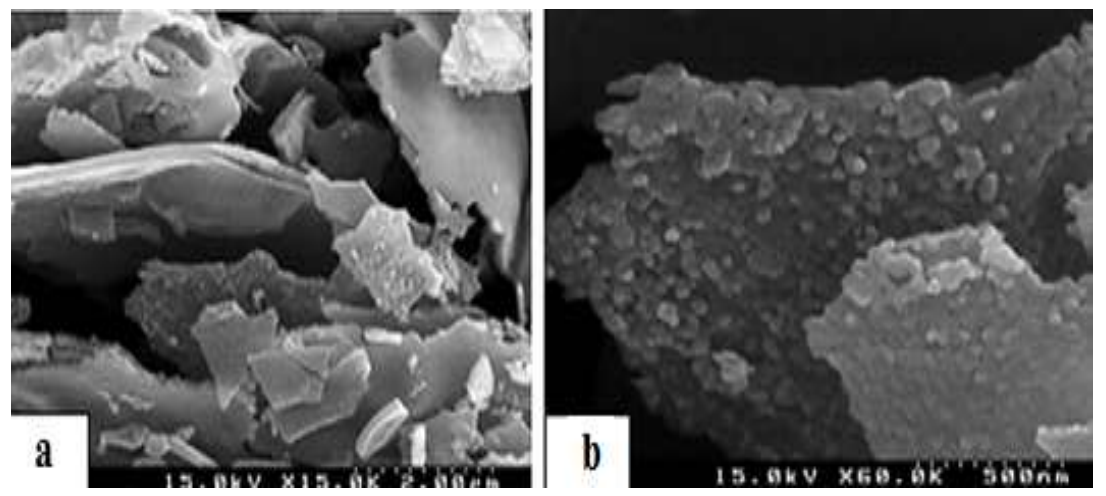

Figure 7: SEM the surface morphology of bulk catalyst with the different resolution a) $2 \mathrm{um}$ b) $500 \mathrm{~nm}$.

The reducibility of $\mathrm{La}_{0.8} \mathrm{Sr}_{0.2} \mathrm{CO}_{0.66} \mathrm{Fe}_{0.34} \mathrm{O}_{3}$ perovskite bulk catalysts was investigated by $\mathrm{H} 2-\mathrm{TPR}$. Figure 8 shows the H2-TPR curves of perovskite catalysts. Autochem 2900 Temperature programmed reduction (TPR) experiments were done in the Micromeritics. The H2-TPR experiments were performed with a 5\% H2/Ar gas flow at 20 standards $\mathrm{cm}^{3} / \mathrm{min}$ and the rate of linear heating was $10^{\circ} \mathrm{C} / \mathrm{min}$ at $40-950{ }^{\circ} \mathrm{C}$ and the $\mathrm{H}_{2}$ rate of gas flow was 10 $\mathrm{ml} / \mathrm{s}$.

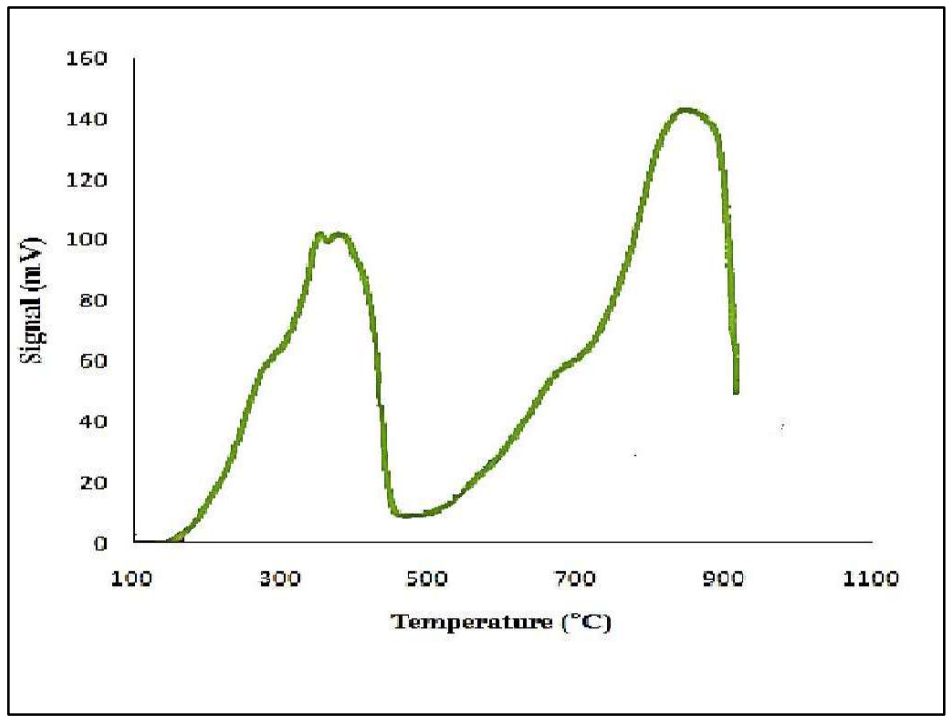

Figure 8: H2-TPR curve of bulk catalyst perovskite. 
The curve of Figure 8 reveals that the $\mathrm{La}_{0.8} \mathrm{Sr}_{0.2} \mathrm{Co}_{0.66} \mathrm{Fe}_{0.34} \mathrm{O}_{3}$ shows two different signal peaks at $346^{\circ} \mathrm{C}$ and $358^{\circ} \mathrm{C}$, the first peak that relates to the reduction of $\mathrm{Co}^{3+}$ to $\mathrm{Co}^{2+}$ at $346^{\circ} \mathrm{C}$ and the second one corresponds to the reduction of $\mathrm{Fe}^{4+}$ to $\mathrm{Fe}^{+3}$ at $358^{\circ} \mathrm{C}$.

\subsection{Mechanism of Surface Reaction}

The activity of perovskite catalysts depends on the oxidation state of the ions for oxidation of toluene and CO, the reduction of the cations of the transfer metal, the empty sites of oxygen concentration, the basic structural defect, and the surface area of a material per unit of mass (specific surface area) [28].

The Mars-Van Krevelen model has been widely used in the kinetic modeling of toluene, CO, or other hydrocarbon catalytic oxidation reactions [29]. This mechanism is based on the idea that adsorption of one molecule $\left(\mathrm{C}_{7} \mathrm{H}_{8}\right.$ or $\left.\mathrm{CO}\right)$ occurs on another molecule $\left(\mathrm{O}_{2}\right)$ that has already been adsorbed on the catalyst. Reaction steps: 1. Adsorption of $\mathrm{C}_{7} \mathrm{H}_{8}$ or $\mathrm{CO}$ on top of adsorbed $\mathrm{O}_{2}$, 2. Adsorption of adsorbed complex 3. Desorption of product $\left(\mathrm{CO}_{2}, \mathrm{H}_{2} \mathrm{O}\right) 4$. Adsorption of $\mathrm{O}_{2}$. We assume our reactions follow from the MVK mechanism. The chemical equation is as follows [30]:

$$
\begin{aligned}
& \mathrm{C}_{7} \mathrm{H}_{8(\mathrm{~g})} \text { or } \mathrm{CO}_{(\mathrm{g})}+\mathrm{O}_{2} \text { ads } \stackrel{\mathrm{\kappa}_{1}}{\rightarrow} \mathrm{CO}_{2(\mathrm{~g})}+\mathrm{H}_{2} \mathrm{O}_{(\mathrm{g})} *[\mathrm{]}] \\
& \text { ads: Adsorbed } \mathrm{O}_{2} \\
& \text { *: Just produced in toluene reaction } \\
& \text { [ ]: Empty site on the surface of the catalyst } \\
& \mathrm{k}_{1} \text { : Rate coefficient }
\end{aligned}
$$

Figure 9 shows that the mechanism of oxidation of toluene on perovskite catalysts. Carbon monoxide is converted to carbon dioxide in the presence of oxygen on perovskite catalysts. In both removal systems, the introduction of $\mathrm{Sr}^{2+}$ in the A-site of perovskite changes the B site ability to reduce cations. Also, on the perovskite surface, the presentation of cations into $A$ sites was detected to increase $O_{\text {adsorbtion }} / O_{\text {lattice }}$ ratio and oxygen vacancy concentration. The catalyst reduces the activation energy and the reaction temperature. Naturally, a higher temperature is required to perform the reaction without the presence of a catalyst.

$$
\begin{gathered}
\mathrm{C}_{7} \mathrm{H}_{8}+9 \mathrm{O}_{2} \stackrel{\text { Catalyst }}{\longrightarrow} 7 \mathrm{CO}_{2}+4 \mathrm{H}_{2} \mathrm{O} \\
\mathrm{CO}+\frac{1}{2} \mathrm{O}_{2} \stackrel{\text { catalyst }}{\longrightarrow} \mathrm{CO}_{2}
\end{gathered}
$$

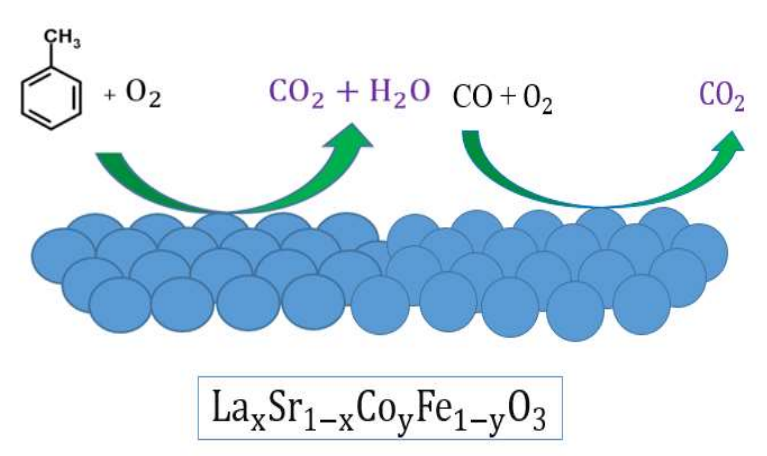

Figure 9: Mechanism of VOC and CO Decomposition on Perovskite.

\subsection{Catalyst Activity Results}

The perovskite catalyst supported on $\gamma$-alumina and ZSM-5 were prepared by different weight percentages containing PE-Al 10\%, PE-Al 20\%, PE-AI 30\%, and PE-Al 40\% catalysts. The activity of all four mentioned catalysts was studied at four temperatures of $280,320,360$ and $400^{\circ} \mathrm{C}$. The results are plotted in Figures 10 and 11. All of the 
tests were reduplicated three times. Therefore, the error bars are shown in the plots. Results revealed that the activity of the catalyst component increases with growing temperature, but the activity of these catalysts is reduced compared to the bulk catalyst itself. Activity depends on the weight percent of the catalyst. The best activities are obtained with PE-AL-40 and PE-Z-40 catalysts. The results were in good agreement with the results available in the literature [31,32], which employed $\mathrm{La}_{0.8} \mathrm{Sr}_{0.2} \mathrm{CoO}_{3-\delta}$ and $\mathrm{LaCoO}_{3}$ catalysts for toluene oxidation process.

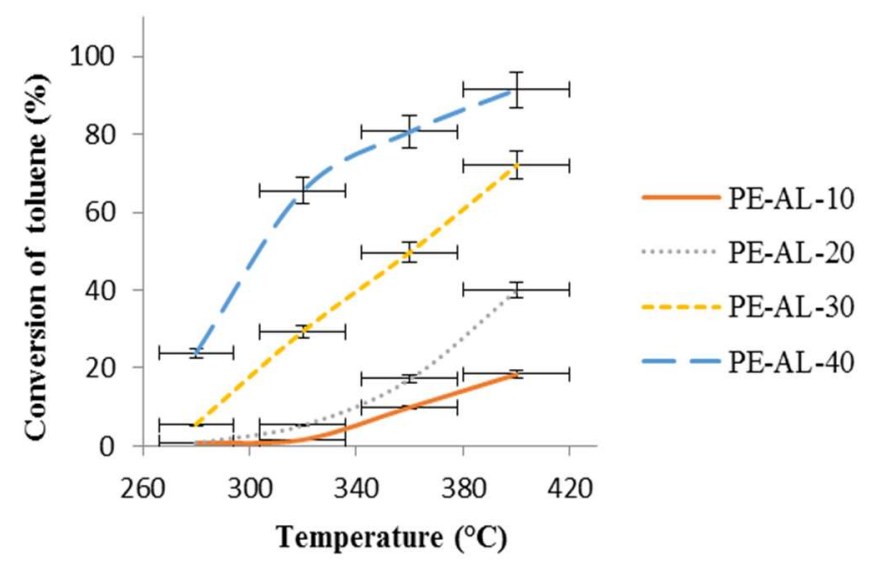

Figure 10: Conversion vs. Temperature of Toluene on Perovskites /Alumina Support.

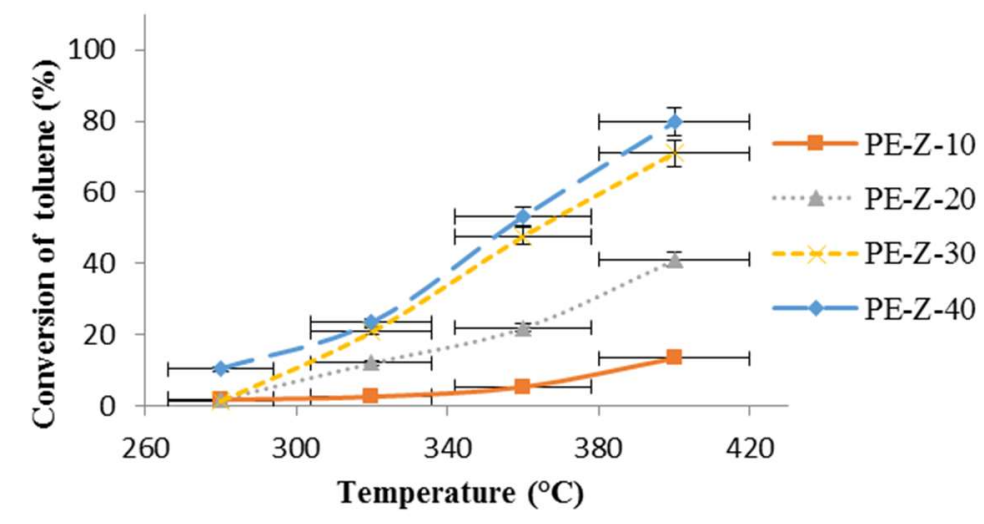

Figure 11: Conversion vs. Temperature of Toluene on Perovskites /ZSM-5 Support.

To investigate the effect of catalyst coating on monolithic substrates, a perovskite catalyst was coated on the $5 \mathrm{~cm}$ length monolith by a dip-coating method. Figure 12 illustrates the comparison of the monolithic catalyst activity concerning bulk powder catalysts.

As shown in Figure 12, the initial activity of the monolithic catalyst is faintly lower than that of the bulk catalyst. Still, with growing temperature, the activity increases so that the temperature required for the entire combustion of toluene occurs at a lower temperature. The complete combustion temperature on the bulk catalyst is $300^{\circ} \mathrm{C}$, but it is reduced to $290^{\circ} \mathrm{C}$ for the monolithic supported catalyst. It should be noted that this increase occurred when the amount of catalyst coated on the monolith was less than half the amount of catalyst tested in the bulk state $\mathrm{CO}_{2}$ and $\mathrm{H}_{2} \mathrm{O}$ are the products at $100 \%$ conversion. This phenomenon indicates the positive effect of the monolith on increasing catalyst activity. As shown in Figure 12, according to the activity curve of the bulk catalyst, results revealed that this perovskite catalyst can completely remove toluene at a temperature of $300^{\circ} \mathrm{C}$. This temperature for $100 \%$ toluene conversion is considered as a basis for comparing the activity of other catalysts.

For the catalytic combustion of CO, alumina, and zeolite (ZSM-5), supported catalysts were prepared in four different weight percentages of 10,20,30, and 40. Of these four catalysts, 10 and $20 \mathrm{wt} \%$ catalysts did not show any activity in removing carbon monoxide, which could be due to the high interaction of the perovskite phase with 
the support. But the other two catalysts with 30 and 40 weight percentages had good reaction activity for the catalytic combustion of $\mathrm{CO}$ as shown in Figures 13 and 14. $\mathrm{CO}_{2}$ is the products at $100 \%$ conversion.

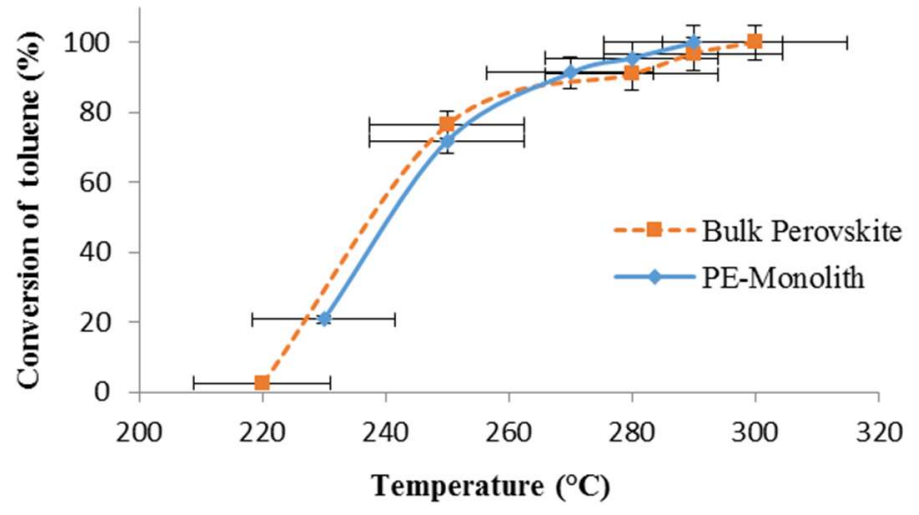

Figure 12: Conversion vs. Temperature of Toluene on Bulk Perovskites \& Perovskite / Monolith.

As shown in Figure 13,40\% Catalyst is $100 \%$ conversion at $350{ }^{\circ} \mathrm{C}$, but for $30 \%$ catalyst is achieved $100 \%$ conversion at $400{ }^{\circ} \mathrm{C}$. Therefore, comparing the activity curve of these catalysts, it is clear that a $40 \%$ catalyst is a more desirable catalyst for the catalytic oxidation of CO.

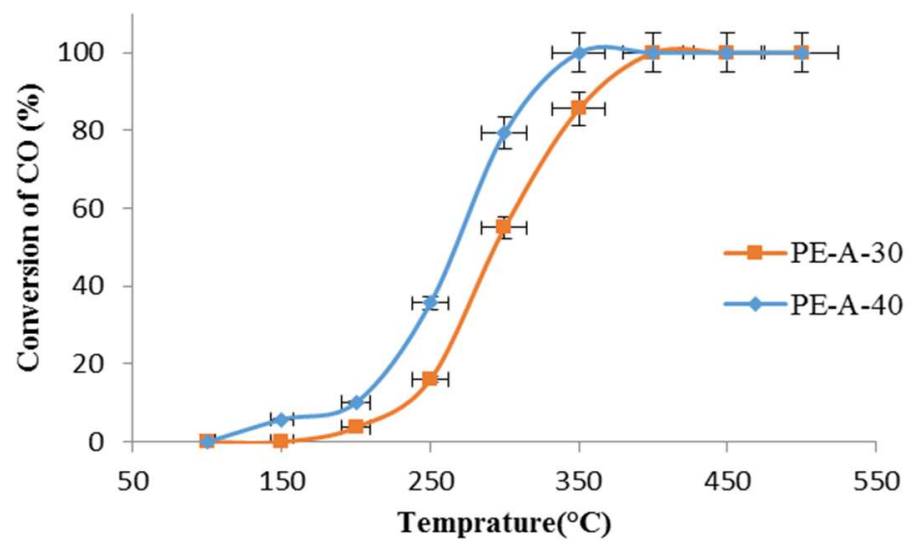

Figure 13: Conversion vs. Temperature of CO on Perovskites /Alumina Support.

As shown in Figure 14, it is perceived that $100 \%$ conversion is achieved for $40 \%$ catalyst at $350^{\circ} \mathrm{C}$. The $30 \%$ catalyst does not perform very well and does not reach $100 \%$ conversion. Therefore, among the catalysts supported on zeolite, $40 \%$ is the desired catalyst for the catalytic oxidation of CO.

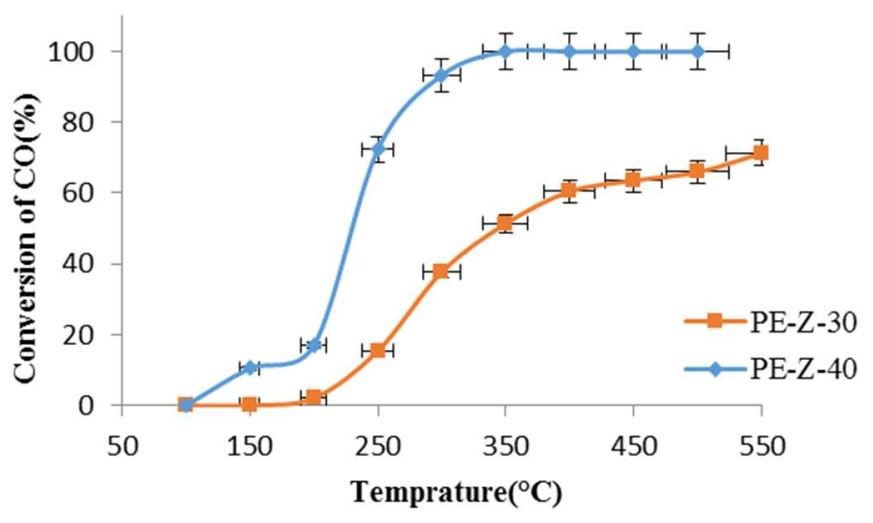

Figure 14: Conversion vs. Temperature of CO on Perovskites /ZSM-5 Support. 
As shown in Figure $15,100 \%$ conversion is achieved for both catalysts at $350{ }^{\circ} \mathrm{C}$, which is similar to the $100 \%$ conversion temperature for the bulk catalyst. But the catalyst supported on zeolite has shown better initial activity. According to the activity curve of the bulk catalyst, it can be seen that this perovskite catalyst can completely remove carbon monoxide. The oxidation reaction temperature of carbon monoxide is $350{ }^{\circ} \mathrm{C}$, concerning the $100 \%$ conversion temperature.

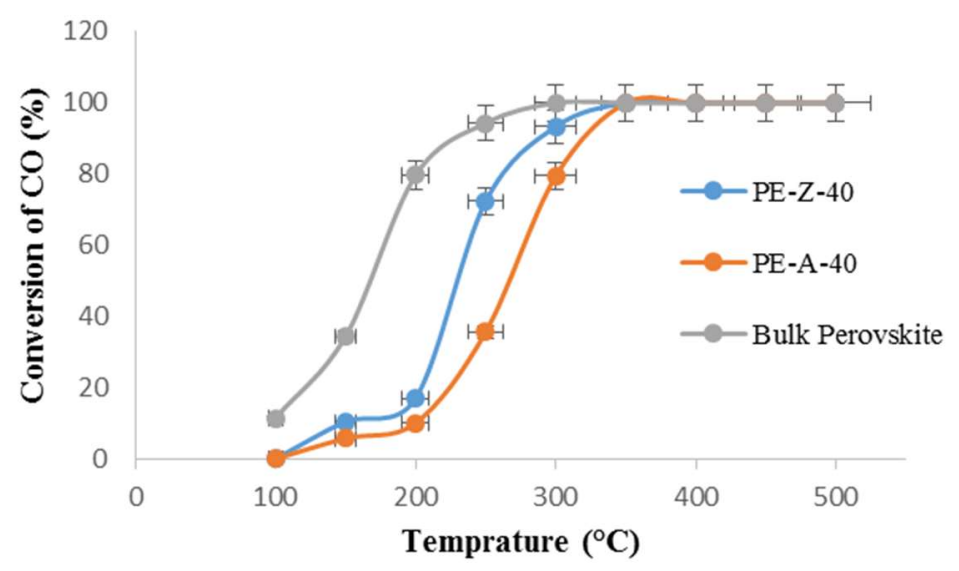

Figure 15: Comparison of the activity of supported catalysts on gamma-alumina and ZSM-5 with Bulk Perovskite.

As shown in Figure 16,100\% conversion is obtained for the monolithic catalyst at $300{ }^{\circ} \mathrm{C}$, which is $50{ }^{\circ} \mathrm{C}$ lower than the temperature of $100 \%$ conversion for the bulk catalyst $\left(350^{\circ} \mathrm{C}\right)$. This activity is achieved while the amount of catalyst coated is half the amount used in each test for the bulk catalyst. Therefore, by coating, this monolith catalyst as a precise thin layer, the surface provided for the gas phase interaction with the catalyst surface is increased and higher activity is obtained.

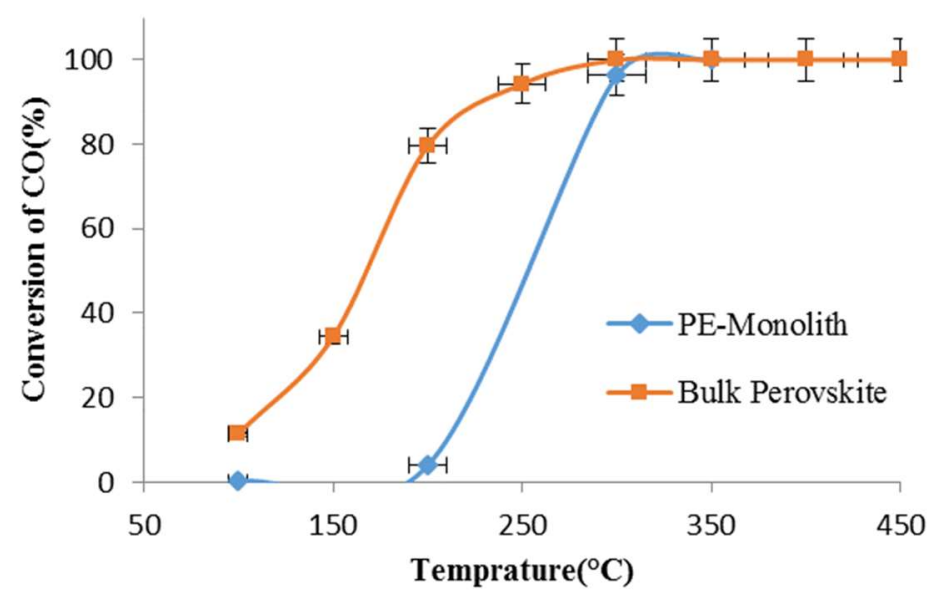

Figure 16: Conversion vs. Temperature of CO on on Bulk Perovskites \& Perovskite / Monolith.

Moreover, the amount of $0.2 \mathrm{~g}$ and $0.09 \mathrm{~g}$ of bulk catalyst and catalyst coated on the monolith is used in each test, respectively. That is, with a lower amount of catalyst consumed, we achieve a better or equal activity. On the other hand, the monolithic supported catalyst has better thermal and mechanical properties. All of the aforementioned obtained results were validated with the literature [33] that has similar results with this work and utilized $\mathrm{LaCOO}_{3}$ for the Catalytic $\mathrm{CO}$ oxidation and $\mathrm{CO}+\mathrm{NO}$ reduction process.

\section{Conclusions}

In this work, a perovskite nano-crystalline structure was effectively synthesized by the sol-gel synthesis technique and coated on gamma $(\gamma)$-alumina and zeolite (ZSM-5) with different weight percent in order to remove 
toluene and carbon monoxide. On the other hand, perovskite catalyst was coated on monolith by dip-coating method. For the mentioned catalysts investigation, this work was performed in three phases including catalysts characterization (XRD, SEM, H2-TPR), the surface reaction mechanism, and catalyst's activity test. The XRD patterns revealed that the crystalline phase was formed. The SEM results indicated that the particle sizes were less than $100 \mathrm{~nm}$. The H2-TPR curves showed two different signal peaks at $346^{\circ} \mathrm{C}$ and $358^{\circ} \mathrm{C}$ representing the reduction of Co and Fe ions, respectively. The impacts of the activity test of these catalysts on the catalytic burning of toluene and $\mathrm{CO}$ in the tubular reactor showed that the supported catalysts have a positive result on the activity of the perovskite. Regarding the results of this test, the alumina supported with $40 \% \mathrm{w} / \mathrm{w}$ perovskite catalyst demonstrate the best performance. On the other hand, the amount of consumption of the catalyst is much lower. For the lower amount of catalyst substance, the catalytic activity is similar or higher than the bulk state. Moreover, the supported catalyst has industrial views and better thermal effects.

\section{Acknowledgments}

We would like to thank Tabriz University and Zonguldak Bülent Ecevit University for their kind cooperation in project planning and support.

\section{Declaration of interest}

There is declared no conflict of interest regarding the publication of this research by the authors.

\section{References}

[1] Forst L, Conroy L-M. Health effects and exposure assessments of VOCs. [M]. Odor and VOC control handbook McGraw-Hill, New York, NY, 3-1, 1998.

[2] Kennes C, María C-V. Conventional biofilters. Bioreactors for waste gas treatment [J]. Springer, Dordrecht, 2001; 47-98.

[3] Ladas S, Poppa H, Boudart M. The adsorption and catalytic oxidation of carbon monoxide on evaporated palladium particles [J]. Surface Science, 1981; 102(1): 151-171. https://doi.org/10.1016/0039-6028(81)90313-7

[4] Scirè S, Liotta L-F. Supported gold catalysts for the total oxidation of volatile organic compounds [J]. Applied Catalysis B: Environmental, 2012; 125, 222-246. https://doi.org/10.1016/j.apcatb.2012.05.047

[5] Luo M, Xian-xin Y, Xiao-ming Z. Catalyst characterization and activity of Ag-Mn, Ag-Co and Ag-Ce composite oxides for oxidation of volatile organic compounds [J]. Applied Catalysis A: General, 1998, 175 (1-2): 121-129.

[6] Ojala S-A. [M]. Catalytic oxidation of volatile organic compounds and malodorous organic compounds, 2005.

[7] Kim H-S, Kim T-W, Koh H-L, et al. Complete benzene oxidation over Pt-Pd bimetal catalyst supported on y-alumina: influence of Pt-Pd ratio on the catalytic activity [J]. Applied Catalysis A: General, 2005; 280(2): 125-131. https://doi.org/10.1016/j.apcata.2004.02.027

[8] Sebastián V, Kumakiri I, Bredesen R, et al. Zeolite membrane for CO2 removal: Operating at high pressure [J]. Journal of Membrane Science, 2007; 292(1-2): 92-97. https://doi.org/10.1016/j.memsci.2007.01.017

[9] Pena M-A, Fierro J-L-G. Chemical structures and performance of perovskite oxides [J]. Chemical reviews, 2001; 101(7): $1981-2018$. https://doi.org/10.1021/cr980129f

[10] Barresi A-A, Mazza D, Ronchetti S, et al. Non-stoichiometry and catalytic activity in ABO3 perovskites: LaMnO3 and LaFeO3 [J]. In Studies in Surface Science and Catalysis. Elsevier. 2000; 130, 1223-1228. https://doi.org/10.1016/S0167-2991(00)80366-3

[11] Dai $\mathrm{H}, \mathrm{He} \mathrm{H}$, Li P, et al. The relationship of structural defect-redox property-catalytic performance of perovskites and their related compounds for CO and NOx removal [J]. Catalysis today, 2004; 90(3-4): 231-244. https://doi.org/10.1016/j.cattod.2004.04.031

[12] Asamoto M, Yahiro H. Catalytic property of perovskite-type oxide prepared by thermal decomposition of heteronuclear complex [J]. Catalysis surveys from Asia, 2009; 13(4): 221-228. https://doi.org/10.1007/s10563-009-9079-3

[13] Zhu Y, Sun Y, Niu X, et al. Preparation of La-Mn-O perovskite catalyst by microwave irradiation method and its application to methane combustion [J]. Catalysis letters, 2010; 135(1): 152-158. https://doi.org/10.1007/s10562-009-0034-8

[14] Gil D-M, Navarro M-C, Lagarrigue M-C, et al. Synthesis and structural characterization of perovskite YFeO3 by thermal decomposition of a cyano complex precursor, $\mathrm{Y}$ [Fe (CN) 6] 4H2O [J]. Journal of thermal analysis and calorimetry, 2011; 103(3): 889-896. https://doi.org/10.1007/s10973-010-1176-z

[15] Aman D, Zaki T, Mikhail S, et al. Synthesis of a perovskite LaNiO3 nanocatalyst at a low temperature using single reverse microemulsion [J]. Catalysis today, 2011; 164(1): 209-213. https://doi.org/10.1016/j.cattod.2010.11.034

[16] Zhang R, Alamdari H, Kaliaguine S. SO2 poisoning of LaFe0. 8Cu0. $2 \mathrm{O} 3$ perovskite prepared by reactive grinding during NO reduction by C3H6 [J]. Applied Catalysis A: General, 2008; 340(1): 140-151. https://doi.org/10.1016/j.apcata.2008.02.028 
[17] Ahmed I, Eriksson S-G, Ahlberg E, et al. Synthesis and structural characterization of perovskite type proton conducting BaZr1- xInxO3$\delta(0.0 \leq x \leq 0.75)$ [J]. Solid State Ionics, 2006; 177(17-18): 1395-1403. https://doi.org/10.1016/j.ssi.2006.07.009

[18] Kirchnerova J, Danilo K. Synthesis and characterization of perovskite catalysts [J]. Solid State lonics, $1999 ; 123$ (1-4): $307-317$.

[19] Lee W-S, Isobe T, Senna M. Synthesis of perovskite $\mathrm{Pb}(\mathrm{Zn} 1 / 3 \mathrm{Nb} 2 / 3) \mathrm{O} 3$ powders via a polymer complex solution route with a large excess of polyethylene glycol [J]. Advanced Powder Technology, 2002; 13(1): 43-54. https://doi.org/10.1163/15685520252900947

[20] Ledoux M-J, Pham-Huu C. Silicon carbide: a novel catalyst support for heterogeneous catalysis [J]. Cattech, 2001;5(4): 226-246. https://doi.org/10.1023/A:1014092930183

[21] Qi S, Zhang W, Li X, et al. Catalytic Oxidation of Toluene Over LaNixB1-xO3 (B= Co, Cu) Perovskite Catalysts, 2021. https://doi.org/10.21203/rs.3.rs-380132/v1

[22] Li X, Chen D, Li N, et al. Highly efficient Pd catalysts loaded on La1- xSrxMnO3 perovskite nanotube support for low-temperature toluene oxidation [J]. Journal of Alloys and Compounds, 2021; 871, 159575. https://doi.org/10.1016/j.jallcom.2021.159575

[23] Liu R, Zhou B, Liu L, et al. Enhanced catalytic oxidation of VOCs over porous Mn-based mullite synthesized by in-situ dismutation [J]. Journal of Colloid and Interface Science, 2021; 585, 302-311. https://doi.org/10.1016/j.jcis.2020.11.096

[24] Yi H, Miao L, Xu J, et al. Palladium particles supported on porous CeMnO3 perovskite for catalytic oxidation of benzene [J]. Colloids and Surfaces A: Physicochemical and Engineering Aspects, 2021; 623, 126687. https://doi.org/10.1016/j.colsurfa.2021.126687

[25] Oskoui S-A, Niaei A, Tseng H-H, et al. Modeling preparation condition and composition-activity relationship of perovskite-type La x Sr1-x Fe y Co1-y O3 nano catalyst [J]. ACS combinatorial Science, 2013; 15(12): 609-621. https://doi.org/10.1021/co400017r

[26] Khanfekr A, Arzani K, Nemati A, et al. Production of perovskite catalysts on ceramic monoliths with nanoparticles for dual fuel system automobiles [J]. International Journal of Environmental Science \& Technology, 2009; 6(1): 105-112. https://doi.org/10.1007/BF03326064

[27] Neacşu I-A, Nicoară A-I, Vasile O-R, et al. Inorganic micro-and nanostructured implants for tissue engineering [J]. In Nanobiomaterials in Hard Tissue Engineering. William Andrew Publishing, 2016; 271-295. https://doi.org/10.1016/B978-0-323-42862-0.00009-2

[28] Tarjomannejad A, Farzi A, Niaei $A$, et al. An experimental and kinetic study of toluene oxidation over LaMn 1- $x$ B $\times 0$ and

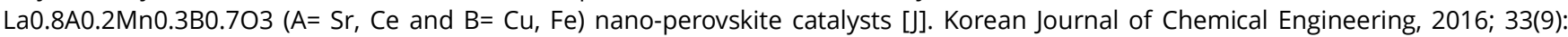
2628-2637.https://doi.org/10.1007/s11814-016-0108-4

[29] Li B, Chen Y, Li L, et al. Reaction kinetics and mechanism of benzene combustion over the NiMnO3/CeO2/Cordierite catalyst [J]. Journal of Molecular Catalysis A: Chemical, 2016; 415, 160-167. https://doi.org/10.1016/j.molcata.2016.01.023

[30] Hagen J. [M]. Industrial catalysis: a practical approach. John Wiley \& Sons, 2015.

[31] Wei Y, Ni L, Li M, et alAcid treated Sr-substituted LaCoO3 perovskite for toluene oxidation [J]. Catalysis Communications, 2021; 155, 106314. https://doi.org/10.1016/j.catcom.2021.106314

[32] Chen $\mathrm{H}$, Wei G, Liang X, et al. Facile surface improvement of LaCoO3 perovskite with high activity and water resistance towards toluene oxidation: Ca substitution and citric acid etching [J]. Catalysis Science \& Technology, 2020; 10(17): 5829-5839. https://doi.org/10.1039/D0CY01150A

[33] Wang S, Xiao P, Xu X, et al. Catalytic CO oxidation and CO+ NO reduction conducted on La-Co-O composites: The synergistic effects between Co3O4 and LaCoO3 [J]. Catalysis Today, 2021; 376, 255-261. https://doi.org/10.1016/j.cattod.2020.05.035 